\title{
Weekly Taxotere and cisplatin with continuous-infusion 5-fluoruracil for the treatment of advanced gastric and esophageal cancer: a prospective, observational, single-institution experience
}

\author{
Paolo Piacentini $\cdot$ Emilia Durante $\cdot$ Annarita Trolese $\cdot$ \\ Anna Mercanti • Andrea Bonetti
}

Received: 29 September 2010/ Accepted: 10 July 2011/Published online: 17 August 2011

(C) The International Gastric Cancer Association and The Japanese Gastric Cancer Association 2011

\begin{abstract}
The combination of Taxotere (docetaxel), cisplatin, and prolonged-infusion 5-fluorouracil (5-FU) has emerged as an active treatment for advanced gastric cancer. However, the regimen proposed by van Cutsem et al. ( $\mathrm{J}$ Clin Oncol 24:4991-7, 2006) is associated with significant toxicity and therefore alternative schedules are needed. In the present study, patients with advanced gastric or esophageal cancer received Taxotere $35 \mathrm{mg} / \mathrm{m}^{2}$ and cisplatin $25 \mathrm{mg} / \mathrm{m}^{2}$ on day 1 , followed by $5-\mathrm{FU} 180 \mathrm{mg} / \mathrm{m}^{2} /$ day as a 7-day prolonged infusion. Drugs were given weekly for 3 consecutive weeks followed by 1 week's rest. Cycles were repeated every 4 weeks. Overall, a total of 110 cycles were administered to 27 patients (median age 63 years, range 40-78 years). The median number of cycles per patient was 4 (range 2-6). Nine partial responses were obtained, resulting in an overall response rate of $33 \%$ [95\% confidence interval (CI) 16-51], a median time to progression of 6.4 months (95\% CI 5.4-7.4), and a median overall survival of 10.7 months (95\% CI 6.6-14.8). Toxicity was mild; grade III-IV neutropenia was the most frequently observed side effect, in 9 administered cycles (8\%); neutropenia was complicated by fever in 2 cycles. Other grade III-IV toxicities observed in $>5 \%$ of patients were anemia and mucositis.
\end{abstract}

P. Piacentini - E. Durante - A. Trolese - A. Mercanti .

A. Bonetti $(\square)$

Department of Medical Oncology, Mater Salutis Hospital,

Azienda Sanitaria Locale n. 21 della Regione Veneto,

Via Gianella 1, 37045 Legnago, Italy

e-mail: andrea.bonetti@aulsslegnago.it
Keywords Advanced gastric and esophageal cancer . Taxotere $\cdot$ Cisplatin $\cdot$ 5-fluorouracil

\section{Introduction}

For patients with advanced gastric cancer, systemic chemotherapy represents the main treatment option because it improves survival as compared with best supportive care [1-4]. A meta-analysis of randomized phase II and III clinical trials evaluating different chemotherapy regimens for the front-line treatment of advanced gastric cancer concluded that the best survival results were achieved with three-drug regimens containing 5-fluorouracil (5-FU), an anthracycline, and cisplatin [5]. However, optimal first-line combination chemotherapy is still controversial and, based on the results of randomized phase III trials, different options are possible. In particular, the demonstrated activity of Taxotere (docetaxel, Aventis Pharma S.A., Antony Cedex, France) both as a single agent [6-8] and in combination $[9,10]$ prompted the conduct of a randomized comparison between a three-drug regimen (Taxotere, cisplatin, and 5-FU) and the two-drug combination of cisplatin and 5-FU, which led to the conclusion that the inclusion of Taxotere was associated with better time to progression (TTP) and overall survival (OS) (the V325 study [11]). However, the significant grade III-IV toxicity associated with this regimen stimulated the evaluation of schedules of administration in which Taxotere (and cisplatin) were given weekly, with the aim of maintaining the strength while attenuating the side effects. We report here our experience with a weekly schedule of Taxotere, cisplatin, and continuous-infusion 5-FU. 


\section{Patients and methods}

\section{Patients}

Entry criteria included the following: a pathologically confirmed diagnosis of metastatic gastric or esophageal cancer for first-line chemotherapy and an Eastern Cooperative Oncology Group (ECOG) performance status of $\leq 2$; and measurable lesion(s) as per modified Response Evaluation Criteria in Solid Tumors (RECIST). Clinical staging was based upon a complete history, physical examination, a routine biochemical profile, a complete blood cell count, carcinoembryonic antigen (CEA) determinations, and the results of a computed tomography (CT) scan performed before the beginning of treatment and then regularly every 2 months.

Treatment schedule

The treatment schedule was: Taxotere $35 \mathrm{mg} / \mathrm{m}^{2}$ diluted in $250 \mathrm{ml}$ normal saline and infused in $60 \mathrm{~min}$ on day 1; cisplatin $25 \mathrm{mg} / \mathrm{m}^{2}$ in $250 \mathrm{ml} \mathrm{NaCl} 3 \%$ and infused in $30 \mathrm{~min}$ on day 1; and 5 -FU $180 \mathrm{mg} / \mathrm{m}^{2} /$ day as a 7 -day prolonged infusion starting on day 1 . For hydration, on day 1 all patients received $1,000 \mathrm{ml}$ of normal saline with $20 \mathrm{mEq} \mathrm{KCl}$ and $500 \mathrm{ml}$ of $5 \%$ dextrose solution with $2 \mathrm{~g}$ magnesium sulfate. Antiemetics used included dexamethasone, metoclopramide, and an HT3 antagonist. Drugs were given weekly for 3 consecutive weeks (one cycle) followed by 1 week's rest. No reduction of drug doses was planned; cycles were delayed if there was myelosuppression (neutrophil count $<1,000$ cells/ $\mu \mathrm{l}$ and/or platelet count $<100,000$ cells/ $\mu \mathrm{l}$ ) or non-hematological toxicity $>$ grade II.

The received dose intensity (DI) was calculated using the method of Hryniuk and Bush [12] and was expressed as $\mathrm{mg} / \mathrm{m}^{2} /$ week.

Study objectives and statistical considerations

This was a prospective, observational study. The primary objective was the response rate (RECIST criteria). The threshold for activity was set at the 0.30 cut-off value. Secondary objectives were safety [National Cancer Institute Common Toxicity Criteria (NCI-CTC), version 3.0], OS and TTP (time from first day of the cycle to progression). OS and PFS were calculated using the KaplanMeyer method.

\section{Results}

From April 14, 2004, to December 31, 2009, 27 patients gave their consent to participate in this study, conducted at the Department of Oncology, Mater Salutis Hospital, Legnago, Italy (Table 1).

Extent of exposure, dose intensity, and cycle delays

Overall, a total of 110 cycles were administered to the 27 patients. The median number of cycles per patient was 4 (range 2-6). Median cumulative doses (ranges) of Taxotere, cisplatin, and 5-FU were $634.7 \mathrm{mg} \quad(240-1,260 \mathrm{mg})$, $452.5 \mathrm{mg}$ (180-900 mg), and 19,684 mg (8,500-42,500 $\mathrm{mg})$, respectively. The number of cycles, cumulative doses, and dose intensities of Taxotere, cisplatin, and 5-FU are listed in Table 2. A cycle delay of $>3$ days was observed in $22 / 110$ cycles $(20 \%)$; the median delay was 7 days (range 4-28). The main causes of delay were myelosuppression (neutrophils $<1,000 \mu$ l or platelets $<100,000 \mu \mathrm{l}$ ) in 9 cycles $(8 \%)$, mucositis, fatigue, and unrelated to the patient's medical condition (e.g., patient's personal reasons, excluding toxicity) (Table 2).

\section{Toxicity}

All patients were assessable for toxicity. Table 3 outlines the grade III-IV toxicities observed during treatment. Grade III-IV neutropenia was the most frequently observed side effect, present in 9 administered cycles (8\%); neutropenia was complicated by fever in 2 cycles. Other grade III-IV toxicities observed in $>5 \%$ of patients were anemia, mucositis, and diarrhea.

Table 1 Patient characteristics

\begin{tabular}{ll}
\hline Number of patients & 27 \\
Male:female & $19: 8$ \\
Age (years) & Median 63 (range 40-78) \\
Performance status (ECOG) & \\
0 & 16 \\
1 & 7 \\
2 & 4 \\
Primary tumor site & \\
Stomach & 22 \\
Esophagus & 5 \\
Histology & 18 \\
Adenocarcinoma, intestinal type & 5 \\
Adenocarcinoma, diffuse & 4 \\
Squamous cell carcinoma & \\
Stage & 3 \\
Locally advanced & 24 \\
Metastatic & \\
Number of metastatic sites & 4 \\
1 & 23 \\
$>1$ &
\end{tabular}

ECOG Eastern Cooperative Oncology Group 
Table 2 Number of cycles and dose intensity (DI)

\begin{tabular}{ll}
\hline Total number of cycles & 110 \\
Median number of cycles/patient & 4 (range 2-6) \\
Number of delayed cycles ( $>3$ days) & $26(24 \%)$ \\
Length of delay (median, days) & 7 (range 4-28) \\
Causes of delay & \\
Myelosuppression & $9(8 \%)$ \\
Mucositis & $5(4.5 \%)$ \\
Fatigue & $3(2.7 \%)$ \\
Fever & $2(1.8 \%)$ \\
Anorexia & $1(1 \%)$ \\
Other (not medical) & $5(4.5 \%)$ \\
Cumulative dose, median (range) & \\
Cisplatin & $452.5 \mathrm{mg}(180-900)$ \\
Taxotere & $633.7 \mathrm{mg}(240-1,260)$ \\
5-FU & $19,684 \mathrm{mg}(8,500-42,500)$ \\
Received DI, median & \\
Cisplatin & $15.3(80 \%)^{\mathrm{a}}$ \\
Taxotere & $20.8(79 \%)^{\mathrm{a}}$ \\
5-FU & $759.5(80 \%)^{\mathrm{a}}$ \\
\hline
\end{tabular}

5-FU 5-fluorouracil

${ }^{a}$ Percentage of the planned DI of cisplatin $\left(18.75 \mathrm{mg} / \mathrm{m}^{2} /\right.$ week $)$, Taxotere $\left(26.25 \mathrm{mg} / \mathrm{m}^{2} /\right.$ week $)$, and 5-FU (945 $\mathrm{mg} / \mathrm{m}^{2} /$ week)

Table 3 Main grade III-IV toxicities per patient and per cycle (\%)

\begin{tabular}{lll}
\hline Toxicity & Per patient, $n(\%)$ & Per cycle, $n(\%)$ \\
\hline Myelosuppression & & \\
Neutropenia & $4(14.8)$ & $9(8)$ \\
Febrile neutropenia & $2(7)$ & $2(1.8)$ \\
Anemia & $2(7.4)$ & $2(1.8)$ \\
Mucositis & $2(7.4)$ & $3(2.7)$ \\
Diarrhea & $1(3.7)$ & $1(1)$ \\
Fatigue & $1(3.7)$ & $1(1)$ \\
Skin (nail changes) & $1(3.7)$ & $1(1)$ \\
Allergic reactions & $1(3.7)$ & $1(1)$ \\
Alopecia & $1(3.7)$ & $1(1)$ \\
\hline
\end{tabular}

\section{Efficacy}

Response to treatment could be evaluated in the whole group of 27 patients. Sixteen patients (59\%; 95\% CI 41-78\%) showed disease stabilization as their best response to treatment, 9 patients $(33 \%$; $95 \%$ CI $16-51 \%)$ had a partial response, and 2 patients (7\%; 95\% CI 0-17\%) showed progressive disease as their best response. One patient was rendered disease-free following the surgical removal of lymph nodes in the lower mediastinum. Upon progression, ten patients received further lines of chemotherapy. As second-line therapy, six patients were treated

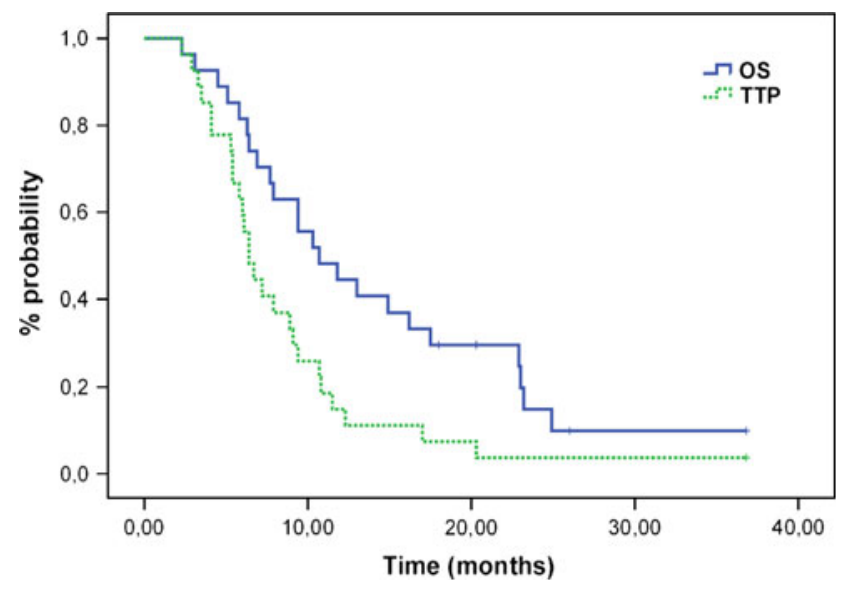

Fig. 1 Overal survival $(O S)$ and time to progression (TTP) curves

according to the simplified FOLFOX regimen (folinic acid, 5-FU bolus, and prolonged infusion of oxaliplatin), while the remaining four patients received capecitabine combined either with irinotecan $(n=2)$ or with oxaliplatin $(n=1)$ or cisplatin $(n=1)$. The median number of cycles given to each patient was 6 (range 4-12). Four patients received further lines of chemotherapy.

The Kaplan-Meier curves for TTP and OS during the protocol are shown in Fig. 1. Median TTP was 6.4 months and median OS 10.7 months. At the time of this analysis 4 patients are still alive ( 3 with disease, 1 with no evident disease).

\section{Discussion}

In patients with advanced gastric cancer the role of chemotherapy is clearly palliative and it is therefore important to reduce the toxicity of treatment while maintaining the efficacy [13]. The high incidence of grade III-IV toxicity reported in the V325 study was confirmed in a 3-arm randomized phase II trial [14] in which Taxotere $(85 \mathrm{mg} /$ $\left.\mathrm{m}^{2}\right)$, cisplatin $\left(75 \mathrm{mg} / \mathrm{m}^{2}\right)$, and continuous-infusion 5 -FU $\left(300 \mathrm{mg} / \mathrm{m}^{2} /\right.$ day, days $\left.1-14\right)$ (TCF) were compared with the combination of Taxotere $\left(85 \mathrm{mg} / \mathrm{m}^{2}\right)$ and cisplatin $\left(75 \mathrm{mg} / \mathrm{m}^{2}\right)$ (TC) and with the combination of epirubicin $\left(50 \mathrm{mg} / \mathrm{m}^{2}\right)$, cisplatin $\left(60 \mathrm{mg} / \mathrm{m}^{2}\right)$, and continuous-infusion 5 -FU $\left(200 \mathrm{mg} / \mathrm{m}^{2} /\right.$ day, days $\left.1-21\right)$ (ECF), with cycles given every 3 weeks in each arm. In the TCF arm, febrile neutropenia and severe diarrhea were experienced by 41 and $15 \%$ of patients, respectively $(n=41)$, higher than the frequencies observed in TC patients $(21$ and $3 \%, n=38)$ and in ECF patients (18 and 6\%, $n=40$ ).

The toxicity of a 3-drug regimen including Taxotere given weekly for 3 consecutive weeks might be reduced by substituting capecitabine for continuous-infusion 5-FU and oxaliplatin for cisplatin, as shown in a small phase I study 
[15], in which the recommended doses (RDs) were: capecitabine $1,000 \mathrm{mg} / \mathrm{m}^{2}$ bid, days $1-14$, Taxotere $60 \mathrm{mg} / \mathrm{m}^{2}$, and oxaliplatin $100 \mathrm{mg} / \mathrm{m}^{2}$, each administered on day 1 . However, the overall toxicity was by no means negligible, because, of the 12 patients treated at the RDs, $25 \%$ suffered neutropenia complicated by fever and $17 \%$ experienced diarrhea.

In the present study, grade III-IV toxicities observed in $>5 \%$ of patients were neutropenia, anemia, and mucositis; febrile neutropenia was observed in only two patients $(7 \%)$. As a result of the good tolerability, the received DI for the three drugs was around $80 \%$ of the planned DI. Toxicity data are in keeping with the data reported by Pasini et al. [16], in which the same regimen as that used in the present study was used as the induction component of a multimodality treatment for operable cancers of the esophagus and the gastroesophageal junction. Several attempts have been made to improve the tolerability of three-drug regimens including Taxotere administered at lower doses and repeated more frequently. Reduced doses of Taxotere $\left(40 \mathrm{mg} / \mathrm{m}^{2}\right)$ and cisplatin $\left(40 \mathrm{mg} / \mathrm{m}^{2}\right)$ given biweekly in combination with the weekly administration of 5-FU $\left(2,000 \mathrm{mg} / \mathrm{m}^{2}\right.$ as a $24-\mathrm{h}$ infusion) and leucovorin $(200 \mathrm{mg} /$ $\mathrm{m}^{2}$ ) were investigated in 60 patients with metastatic $(n=36)$ or locally advanced $(n=24)$ cancer of the stomach or the gastroesophageal junction [17]. In that study, febrile neutropenia was observed in only 5\% of patients, while grade III-IV diarrhea and lethargy were reported in $20 \%$ and $18 \%$ of patients, respectively. The particularly favorable outcome of patients, with an OS of 17.9 months, was probably due to the high percentage of locally advanced cases. In the ATTAX trial, a randomized phase II study [18], 106 patients with gastric or esophageal cancer received either weekly Taxotere $\left(30 \mathrm{mg} / \mathrm{m}^{2}\right.$, days 1 and 8) combined with cisplatin $\left(60 \mathrm{mg} / \mathrm{m}^{2}\right.$, day 1$)$ and continuous infusion $5-\mathrm{FU}\left(200 \mathrm{mg} / \mathrm{m}^{2} /\right.$ day, days $\left.1-21\right)$ (wTCF) or weekly Taxotere according to the same dose and schedule as above, combined with capecitabine (800 $\mathrm{mg} / \mathrm{m}^{2}$ bid, days $\left.1-14\right)$ (wTX); in both arms cycles were repeated every 3 weeks. Weekly TCF was associated with a higher overall response rate (ORR) (49 vs. 26\%), and a longer OS (12.8 vs. 10.1 months); toxicity was mild: febrile neutropenia in $4 \%$ of patients, and stomatitis, diarrhea, and fatigue in 22,10 , and $10 \%$ of patients, respectively. The favorable toxicity profile of reduced doses of Taxotere $\left(50 \mathrm{mg} / \mathrm{m}^{2}\right.$, day 1) given biweekly with leucovorin $\left(200 \mathrm{mg} / \mathrm{m}^{2}\right.$, day 1$)$ and $24-\mathrm{h}$ continuous-infusion 5 -FU $\left(2,600 \mathrm{mg} / \mathrm{m}^{2}\right)$ was confirmed in a study (FLOT) in which oxaliplatin $\left(85 \mathrm{mg} / \mathrm{m}^{2}\right.$, day 1$)$ was given as a substitute for cisplatin [19], following the results of a phase III trial [20] showing that the biweekly administration of oxaliplatin $85 \mathrm{mg} / \mathrm{m}^{2}$, leucovorin $200 \mathrm{mg} / \mathrm{m}^{2}$, and 5 -FU $2,600 \mathrm{mg} / \mathrm{m}^{2}$ via $24-\mathrm{h}$ infusion (FLO) was associated with reduced toxicity and perhaps improved activity compared to a regimen including cisplatin $50 \mathrm{mg} / \mathrm{m}^{2}$ (every 2 weeks), leucovorin $200 \mathrm{mg} / \mathrm{m}^{2}$, and 5 -FU $2,000 \mathrm{mg} / \mathrm{m}^{2}$ via 24-h infusion (weekly) (FLP). The FLOT trial was conducted in 59 patients with locally advanced $(n=4)$ or metastatic $(n=55)$ adenocarcinoma of the stomach or the gastroesophageal junction. With an ORR observed in $57.7 \%$ of patients and a median OS of 11.1 months, febrile neutropenia, grade III-IV diarrhea, and fatigue were present in $1.9,14.8$, and $11.1 \%$ of patients, respectively.

In conclusion, the weekly administration of Taxotere and cisplatin with continuous-infusion 5-FU is associated with a toxicity profile that compares favorably with other published three-drug regimens including Taxotere, cisplatin (or oxaliplatin), and a fluoropyrimidine. According to the metanalysis carried out by Wagner et al. [5], a triplet should be preferred as first-line regimen for patients with advanced gastric cancer. However, at present it is not clear which, among the three-drug regimens including Taxotere or epirubicin, is the best to propose in this setting. Furthermore, we believe that further efforts should be addressed toward developing new drugs/combinations rather than performing comparisons of existing regimens.

\section{References}

1. Murad AM, Santiago FF, Petroianu A, et al. Modified therapy with 5-fluorouracil, doxorubicin, and methotrexate in advanced gastric cancer. Cancer. 1993;72:47-51.

2. Pyrhönen S, Kuitunen T, Nyandoto $P$, et al. Randomised comparison of fluorouracil, epidoxorubicin and methotrexate (FEMTX) plus supportive care with supportive care alone in patients with non-resectable gastric cancer. Br J Cancer. 1995;71:587-91.

3. Scheithauer W, Kornek G, Hejna M, et al. Palliative chemotherapy versus best supportive care in patients with metastatic gastric cancer: a randomized trial. Ann Hematol. 1994;73:A181 (suppl 2, abstr).

4. Glimelius B, Ekstrom K, Hoffman K, et al. Randomized comparison between chemotherapy plus best supportive care with best supportive care in advanced gastric cancer. Ann Oncol. 1997;8:1-6.

5. Wagner AD, Unverzagt S, Grothe W, et al. Chemotherapy for advanced gastric cancer. Cochrane Database Syst Rev. 2010;(3):CD004064. doi:10.1002/14651858.CD004064.pub3.

6. Sulkes A, Smyth J, Sessa C, et al. Docetaxel $\left(\right.$ Taxotere $^{\mathrm{TM}}$ ) in advanced gastric cancer: results of a phase II clinical trial. Br J Cancer. 1994;70:380-3.

7. Mavroudis D, Kourousis C, Androulakis N, et al. Frontline treatment of advanced gastric cancer with docetaxel and granulocyte colony-stimulating factor (G-CSF): a phase II trial. Am J Clin Oncol. 2000;23:341-4.

8. Graziano F, Catalano V, Baldelli AM, et al. A phase II study of weekly docetaxel as salvage chemotherapy for advanced gastric cancer. Ann Oncol. 2000;11:1263-6.

9. Roth AD, Maibach R, Martinelli G, et al. Docetaxel (Taxotere)cisplatin (TC): an effective drug combination in gastric carcinoma. Swiss Group for Clinical Cancer Research (SAKK), and 
the European Institute of Oncology (EIO). Ann Oncol. 2000;11:301-6.

10. Ridwelski K, Gebauer T, Fahlke J, et al. Combination chemotherapy with docetaxel and cisplatin for locally advanced and metastatic gastric cancer. Ann Oncol. 2001;12:47-51.

11. Van Cutsem E, Moiseyenko WM, Tjulandin S, et al. Phase III study of docetaxel and cisplatin plus fluorouracil compared with cisplatin and fluorouracil as first-line therapy for advanced gastric cancer: a report of the V325 study group. J Clin Oncol. 2006;24:4991-7.

12. Hryniuk W, Bush H. The importance of dose intensity of chemotherapy of metastatic breast cancer. J Clin Oncol. 1984;2: 1281-8.

13. Al-Batran SE, Ajani JA. Impact of chemotherapy on quality of life in patients with metastatic esophagogastric cancer. Cancer. 2010;116:2511-8.

14. Roth AD, Fazio N, Stupp R, et al. Docetaxel, cisplatin, and fluorouracil; docetaxel and cisplatin; and epirubicin, cisplatin, and fluorouracil as systemic treatment for advanced gastric carcinoma: a randomized phase II trial of the Swiss Group for Clinical Cancer Research. J Clin Oncol. 2007;25(22):3217-23.

15. Sym SJ, Ryu M-H, Kang HJ, et al. Phase I study of 3-weekly docetaxel, capecitabine and oxaliplatin combination chemotherapy in patients with previously untreated advanced gastric cancer. Cancer Chemother Pharmacol. 2010;66:373-80.
16. Pasini F, de Manzoni G, Pedrazzani C, et al. High pathological response rate in locally advanced esophageal cancer after neoadjuvant combined modality therapy: dose finding of a weekly chemotherapy schedule with protracted venous infusion of 5 -fluorouracil and dose escalation of cisplatin, docetaxel and concurrent radiotherapy. Ann Oncol. 2005;16:1133-9.

17. Lorenzen S, Hentrich M, Haberl C, et al. Split-dose docetaxel, cisplatin and leucovorin/fluorouracil as first-line therapy in advanced gastric cancer and adenocarcinoma of the gastroesophageal junction: results of a phase II trial. Ann Oncol. 2007;18:1673-9.

18. Tebbutt NC, Cummins MM, Sourjina T, et al. Randomised, noncomparative phase II study of weekly docetaxel with cisplatin and 5-fluorouracil or with capecitabine in oesophagogastric cancer: the AGITG ATTAX trial. Br J Cancer. 2010;102:475-81.

19. Al-Batran SE, Hartmann JT, Hofheinz R, et al. Biweekly fluorouracil, leucovorin, oxaliplatin, and docetaxel (FLOT) for patients with metastatic adenocarcinoma of the stomach or esophagogastric junction: a phase II trial of the Arbeitsgemeinschaft Internistische Onkologie. Ann Oncol. 2008;19:1882-7.

20. Al-Batran SE, Hartmann JT, Probst S, et al. Phase III trial in metastatic gastroesophageal adenocarcinoma with fluorouracil, leucovorin plus either oxaliplatin or cisplatin: a study of the Arbeitsgemeinschaft Internistische Onkologie. J Clin Oncol. 2008;26:1335-442. 